\title{
Retraction Note: Electrophoresis separation and electrochemical detection on a novel thread-based microfluidic device
}

\author{
Yi-Chi Wei $\cdot$ Lung-Ming Fu $\cdot$ Che-Hsin Lin
}

Published online: 28 May 2013

(C) Springer-Verlag Berlin Heidelberg 2013

Retraction to: Microfluid Nanofluid (2013) 14:723-730

DOI 10.1007/s10404-012-1091-7

Due to a production error, this article appears already at pp. 583-590 (DOI 10.1007/s10404-012-1076-6) of the same issue of the same journal and is therefore retracted.

The online version of the original article can be found under doi:10.1007/s10404-012-1091-7.

Y.-C. Wei · C.-H. Lin $(\bowtie)$

Department of Mechanical and Electro-Mechanical Engineering, National Sun Yat-sen University, Kaohsiung 804, Taiwan, ROC

e-mail: chehsin@mail.nsysu.edu.tw

L.-M. Fu

Graduate Institute of Materials Engineering, National Pingtung University of Science and Technology, Pingtung 912, Taiwan, ROC 